\title{
ESPACIO PARA RESPIRAR: GEORGE FLOYD, LA PLAZA BLM Y LA MONUMENTALIZACIÓN DE LOS PAISAJES ESTADOUNIDENSES URBANOS DIVIDIDOS
}

\author{
SPACE TO BREATHE: GEORGE FLOYD, BLM PLAZA AND THE \\ MONUMENTALIZATION OF THE DIVIDED AMERICAN CITYSCAPES
}

\author{
Cameron McCarthy \\ Global Studies in Education Division \\ University of Illinois \\ cmccart1@illinois.edu \\ Nubras Samayeen \\ Department of Landscape Architecture \\ University of Illinois \\ samayee2@illinois.edu \\ Adrian Wong \\ Institute of Communication Research \\ University of Illinois \\ adrianw3@illinois.edu
}

Resumen: Este artículo pretende ser una respuesta abiertamente polémica al asesinato de George Floyd, autorizado por el Estado, y a la propulsión de las luchas de Black Lives Matter en los Estados Unidos y en todo el mundo. Aborda específicamente estos asuntos en el marco de la controvertida monumentalización y consagración de la supremacía blanca en la codificación del espacio construido en las ciudades de los Estados Unidos. Se argumenta que tal monumentalización ha provocado una guerra por los signos. Profundizando en el significado bifurcado del renombramiento de Lafayette Square como BLM Plaza en Washington DC, el ensayo gira en torno a una consideración reflexiva de la larga historia de tales luchas y su significado material y simbólico para la promoción en EE.UU. de un modelo de modernización sin fricciones y de la teoría de la modernización a los habitantes del Sur Global y su actual insistencia en una agenda neoliberal para las ciudades de EE.UU. que ha dado lugar a la expulsión racial de los cuerpos negros y morenos del centro de la ciudad.

Palabras clave: George Floyd, Luchas de Black Lives Matter, Monumentalización, Modernidad, Espacio Público.

Abstract: This article is intended to be an openly controversial response to the statesanctioned assassination of George Floyd, and the propulsion of Black Lives Matter 
struggles in the United States and around the world. It specifically addresses these issues within the framework of the controversial monumentalization and enshrinement of white supremacy in the codification of built space in the cities of the United States. It is argued that such monumentalization has sparked a war for signs. Delving into the bifurcated significance of the renaming of Lafayette Square as BLM Plaza in Washington DC, the essay revolves around a thoughtful consideration of the long history of such struggles and their material and symbolic significance for the US promotion of a model. of frictionless modernization and modernization theory to the inhabitants of the Global South and its current insistence on a neoliberal agenda for US cities that has resulted in the racial expulsion of black and brown bodies from the center of the city.

Key Words: George Floyd, Black Lives Matter Struggles, Monumentalization, Modernity, Public Space.

"Los hombres que más hablan del valor de Lee y de la sangre de los valientes muertos confederados son los que nunca han olido pólvora ni se han enfrentado a una batalla. La mayoría de ellos estaban en una mesa, ya sea encima o debajo de ella cuando la guerra estaba en marcha..." (John Mitchell, concejal negro de Richmond City, siglo XIX, citado en Griego, 2015)

"No puedo respirar." (George Floyd, 25 de mayo de 2020)

“La esperanza se inventa todos los días.” (James Baldwin citado en Adelsen, 1970, p. 46)

\section{INTRODUCCIÓN}

La muerte de George Floyd a manos de la policía de Minneapolis y la erupción de protestas a gran escala, tanto nacionales como internacionales que provocó, pusieron en evidencia las preguntas que persistían sobre el orden político y democrático en los Estados Unidos. La lucha negra, desde la esclavitud hasta el presente, siempre ha tenido un efecto generador en la cultura y el espíritu más amplio y en la propia identidad de los Estados Unidos como comunidad imaginada. Ha provocado las más profundas preguntas sobre nuestra humanidad e identidad en una nación que disimula sus prácticas racistas y coloniales con el fin de proclamarse, con bombos y platillos, como un modelo purificado para el mundo. En efecto, la tortura pública de Floyd, su ejecución por la policía que opera dentro y fuera de los límites de la ley, es otro desgarrador recordatorio de la provocadora afirmación de Bruno Latour de que incluso en el caso de las sociedades más avanzadas (Estados Unidos incluido): "nunca hemos sido modernos". (Latour, 1993, p. 10) Una vez más, se ha suscitado la cuestión, nunca completamente sedimentada, de la imagen que Estados Unidos tiene de sí mismo ante el mundo. En particular, ha puesto al descubierto la cuestión de la modernidad incompleta de Estados Unidos y el carácter desigual y asimétrico de las relaciones raciales y las relaciones sociales en general dentro del país. Un punto central de esta impugnación se ha articulado a la vida de la ciudad y, especialmente, al espacio urbano, donde durante las últimas décadas, como en la Primavera Árabe, los habitantes de las ciudades han coordinado 
activamente su juicio negativo sobre los programas de gentrificación neoliberal, que siguen amenazando su propia supervivencia existencial en nuestras ciudades. De hecho, los últimos decenios de "desarrollo" y "renovación" urbanos han acelerado incesantemente la expulsión y eliminación de los pobres negros y morenos del corazón de la ciudad. Esto ha hecho de la ciudad un lugar de permanente disputa; y mientras quede una voluntad de dignidad en la vida social, la revolución será permanente. Porque los autores creen firmemente que cuando la revolución alcance una masa crítica en los Estados Unidos, se desviará desde el perverso y agitado centro de la ciudad.

Por lo tanto, en lo que sigue en este documento, tratamos de dibujar una línea clave de esta disputa continua sobre los símbolos suturados de la vida moderna en Estados Unidos, y las persistentes condiciones racializadas de los negros y morenos dentro de ella, que la muerte de Floyd y la protesta por ella han provocado. Específicamente, nos centramos en lo que deja clara la lucha sobre la espacialización que la declaración del espacio-santuario de la recientemente llamada Black Lives Matter Plaza (BLM Plaza) en Washington D.C., justo en frente de la Casa Blanca. Sostenemos que esta poderosa reinserción simbólica de un amplio apoyo social y cívico a la lucha negra en el espacio de la ciudad como respuesta a la muerte de Floyd, en un área de los bienes raíces más prominentes de los EE.UU., no sólo afirma la dignidad de las vidas de los negros y los morenos. También releva una lucha por el alma de la modernidad de los EE.UU. en las articulaciones de su espacio construido. Esta lucha tiene que ser continuamente reiniciada y sostenida ya que existe un persistente agravamiento derivado del impulso autoritario popular de consagrar el espacio público como plataforma para la aplicación de una supremacía blanca visible. Esta contienda sobre el paisaje dividido de este país surge de la construcción y monumentalización del espacio en el enigma que es el pasado y el presente de Estados Unidos. Impulsado por estos acontecimientos, que son el impulso del asesinato con licencia estatal de Floyd, este documento insta a reconsiderar la raza y el espacio en relación con la monumentalización del paisaje dividido de E.E.U.U. Pedimos a los lectores que consideren lo que se ha codificado en el espacio construido de Estados Unidos. Imploramos a nuestros lectores que observen directamente la "geometría del poder" (Massey, 1993) incrustada en este paisaje, en particular la perpetuación de la subversión de la vida y el pasado negro en la supremacía blanca afirmada por el estado, que tal monumentalización autoriza y significa. 


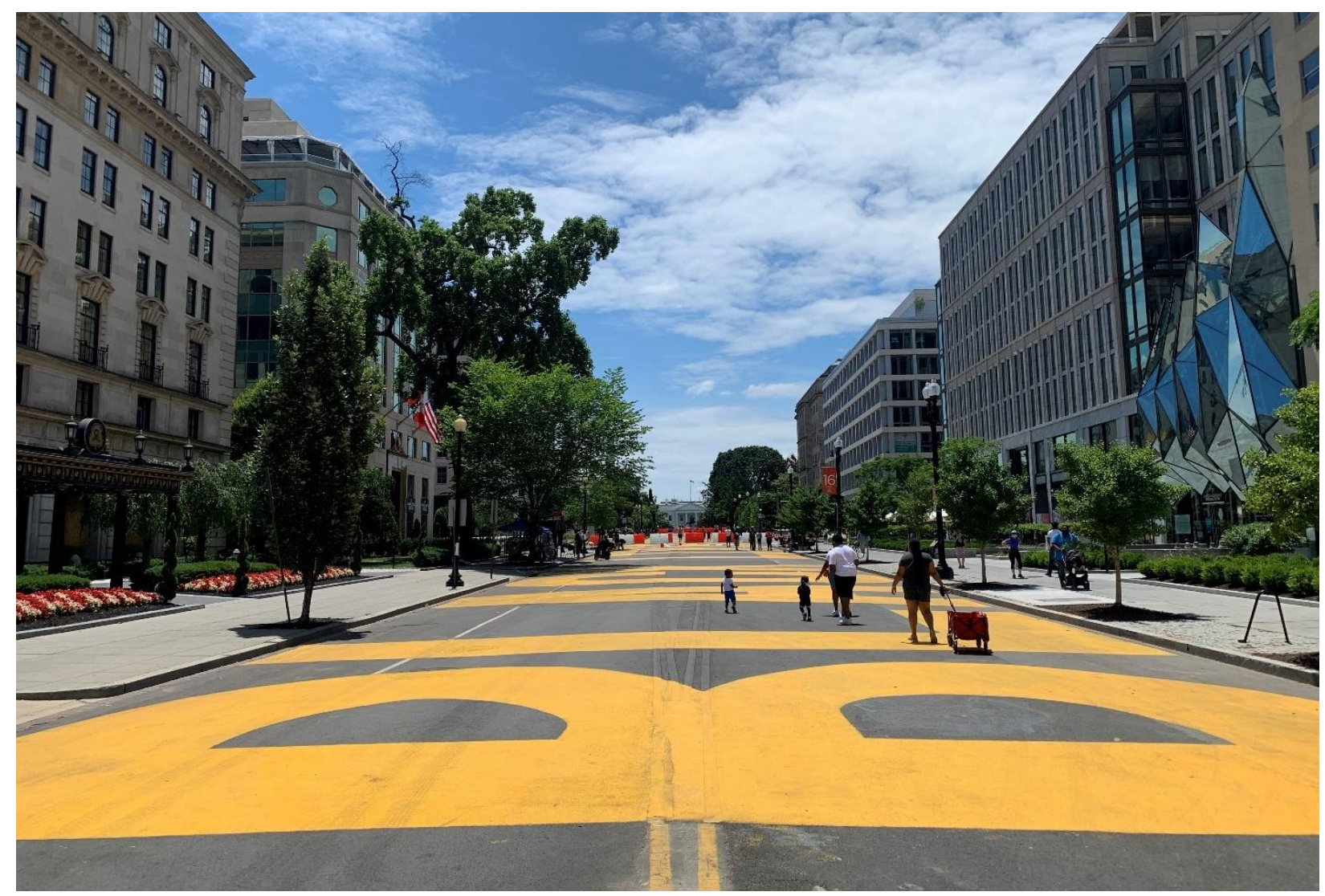

Figura 1. "Black Lives Matter (BLM)" escrito en el pasillo de la calle 16 de Columbia. Foto cortesía de Stephanie Leedom

\section{EL CONTEXTO: BLM PLAZA COMO RESPUESTA A LA EXPULSIÓN DE LOS NEGROS}

La historia de la ejecución extrajudicial de George Floyd a manos de la policía sirvió para recordar que, desde el primer momento del colonialismo en suelo americano, las prácticas de los "agentes estatales estadounidenses" y sus precursores se han dedicado incesantemente a un asalto asesino contra las vidas negras e indígenas y a una avaricia desenfrenada por expropiar todas las tierras y recursos naturales. Este "recordatorio" y su respuesta popular existen en dos polos separados de la lucha de Estados Unidos con su hipocresía, su proclamación engañosa de la modernidad y su persistente consentimiento de la supremacía blanca en la organización y monumentalización del espacio construido. Desde que nuestra nación alcanzó la mayoría de edad, bailando en el salón a través de la esclavitud, la expropiación, la colonización y el asesinato generalizado, la lucha de los negros y los indígenas por el espacio para respirar, que se esfuerzan como gravámenes contra una marea cada vez mayor, siempre se ha topado con el credo culturalmente excepcionalista y la noción descuidada del "salto sin fricción" de América hacia la modernidad. Los burócratas y científicos sociales estadounidenses, como Talcott Parsons y W.W. Rostow, ensalzaron este salto asesino al mundo, especialmente en los programas de modernización, la teoría de la modernización y la propuesta de un desarrollo constante que debía extenderse a todos los 
países que pudieran "desnudar el mercado", especialmente en el Sur global desde la época de la Guerra Fría (Gilman, 2003).

Comenzamos nuestra exploración de los acontecimientos actuales en relación con Floyd y su significado para nuestra reevaluación de la orquestación del espacio en los prominentes paisajes urbanos de este país, revisando los hechos crudos. En ese fatídico Día de la Conmemoración, el lunes 25 de mayo de 2020, George Floyd, un hombre negro de 46 años de edad, fue arrestado por intentar, supuestamente, hacer pasar un billete falso de veinte dólares en una tienda de conveniencia en Minneapolis, Minnesota. El arresto terminó con la abominable muerte de Floyd, una ejecución pública y extrajudicial, a manos de la policía. El video gráfico de los últimos momentos de Floyd, esposado, sin vida, mientras tres policías se sentaban en su espalda, mientras que un cuarto le cerraba el paso de aire con una rodilla en el cuello, catapultó este asesinato policial ensayado de hombres negros a la volátil esfera de los medios de comunicación, vaporizando la distinción entre los viejos y los nuevos medios más rápido de lo que tarda el estado en matar a un hombre. Mientras el clip de este horrible evento ardía a través de las redes sociales y todos los principales medios de comunicación, el país entero estalló de nuevo en explosivas e indignadas protestas contra la cantinela de la brutalidad policial y la violencia ejecutada por el Estado. Rebotando por todo el país y, de hecho, el planeta, éstas se convertirían en un floreciente centro de gravedad para el movimiento Black Lives Matter, que el derechista Director General de la Casa Blanca, Donald J. Trump, llamó, desconcertantemente, "un símbolo de odio" (Donald J. Trump), evidencia de los intentos del Estado de los Estados Unidos de justificar la violencia de la supremacía blanca. Se precipitó una resistencia feroz como no se había visto en los Estados Unidos desde los años sesenta. Y con la vehemente movilización pública en pleno apogeo, la ira por más de 400 años de violencia de los blancos y los colonos ardió en la capital de la nación, Washington, D.C.

Con esta presión propulsora, estos acontecimientos provocaron una sorprendente recodificación simbólica del espacio en la capital de la nación, a petición de una ciudad. El viernes 5 de junio de 2020, la alcaldesa de Washington D.C. encargó a los trabajadores de la ciudad que pintaran el histórico corredor axial de la calle 16 del Distrito de Columbia con palabras amarillas masivas, a lo largo de toda la calle: "Black Lives Matter (BLM)" (Willingham, Fig. 1). Así surgió un nuevo espacio en la capital y en el imaginario nacional de la comunidad negra de Estados Unidos. Registrándose en las bodegas de vinos y salones de caviar a través de Washington D.C. como un grito del alma por una nueva dispensación, ciertos bastiones de la supremacía blanca, como la Casa Blanca de Trump, respondieron con enojo, temerosos del más mínimo gesto que pudiera manchar su hipócrita fachada "moderna". En la calle y en las paradas de autobús, las bibliotecas, los bancos del parque y las salas de chat del mundo entero, los esfuerzos de la alcaldesa se han leído como otra "distracción" más, invocada dramáticamente para disimular las falsas promesas de acción de la ciudad (BlackLivesMatter DC). Aunque simbólicamente provocativo como un mordisco para los medios de comunicación de los Estados Unidos, que siempre trabajan para provocar mientras dan un zarpazo a la narrativa popular para volver a un cómodo statu quo, las acciones encargadas por la alcaldesa de la ciudad fueron una sustitución de un cambio real. La alcaldesa apenas ha mostrado una inclinación a "desfinanciar a la policía", una demanda fundamental para la mayoría de nuestras recientes protestas, y un grito de guerra que ha galvanizado y puesto voz a las verdaderas necesidades de las comunidades saturadas de 
policías, violadas por el estado y sin dinero. El grito de cambio material ha sido, y será siempre, el único llamado verdadero de las comunidades desposeídas y marginadas en los EE.UU. y en todo el mundo.

Un mural puede proclamar, pero no habla como el dinero. Como tal, el símbolo de la alcaldesa opera en la esfera política y no en la social. Es una declaración de un régimen político contra otro. Es una declaración de los demócratas contra los republicanos, y funciona más como un esfuerzo de los políticos liberales para intentar, sin esperanza, desheredar la tensa trayectoria de nuestra nación. No es, desafortunadamente, ningún tipo de afirmación de que las condiciones financiadas, ordenadas y ejecutadas por el estado que causaron la muerte de Floyd, y la muerte de casi 1.100 americanos en 2019 (Higgins y Schoen), llegarán a su fin en cualquier momento. Reconociendo el mural de la alcaldesa como un intento de distraer a los organizadores del verdadero trabajo a realizar, los manifestantes "reclamaron el mensaje, repintando el mural para decir, 'Las Vidas negras importan = Desfinanciar la policía'" (Project for Public Spaces). La alcaldesa y su reparto de apoyo no son los magos que pueden pensar que son, porque nuestra gente conoce los trucos, y recuerdan el juego descorazonador. Las protestas no son conferencias y no son sesiones legislativas. El punto no es crear palabras sino usar las palabras para crear acción. La única declaración que importa es la "charla" del dinero, "Desfinanciar a la policía"; no las palabras de una alcaldesa, tratando de convertirse en una fanática siete años más tarde. Estos eventos polarizantes demuestran los proyectos semióticos multinivel que simbolizan la movilización. Mientras que muchos, y especialmente los "liberales blancos", aplaudieron los esfuerzos de la alcaldesa (BlackLivesMatter DCa), BlackLivesMatter DC reconoció lo que significaba para las circunstancias sociales reales de todo el país: la alcaldesa no iba a seguir adelante con ninguna forma de "democracia de la abolición" en un futuro próximo (Davis, 2011). El pueblo tendrá que seguir presionando.

En el plano nacional, y ciertamente en el terreno de la legibilidad de Trump y del partido republicano, el intento de este signo de disipar los llamados sociales a un cambio real permaneció en gran medida sin ser reconocido. A este nivel, el signo conservó su registro descaradamente hipócrita, afirmando decir la verdad al poder. La histórica calle 16 se extiende como un eje central en dirección sur que termina en el pórtico norte de la Casa Blanca, Lafayette Square, donde la estatua ecuestre del presidente genocida de los Estados Unidos Andrew Jackson se alza desde el centro con una línea de visión directa (Loring, 2017). Jackson, cuya imagen grabada en un billete de veinte dólares creó la oportunidad de otra ejecución estatal, el asesinato de Floyd; dio a luz el genocidio de los nativos americanos en el sudeste de los Estados Unidos, exaltó la discriminación racial y dirigió un constante bombardeo estatal contra los movimientos antiesclavistas y abolicionistas. El mismo día en que la alcaldesa encargó que se pintara "Black Lives Matter", el 5 de junio, la plaza de Lafayette, de más de un siglo de antigüedad, fue rebautizada oficialmente "Black Lives Matter Plaza", con su propio letrero de la ciudad. Esta renovación urbana se llevó a cabo mediante textos, la eliminación de estatuas icónicas y el renombramiento de la plaza, provocando una extraordinaria transfiguración del espacio consagrado en el registro nacional. Estableció la visibilización de un nuevo orden político que luchaba por nacer e impulsó un cuestionamiento oblicuo de la disposición del espacio urbano de los Estados Unidos. De un régimen político a otro, jugando juegos de retórica de poder por el destino de una inminente elección presidencial de los Estados Unidos, fue un ejemplo notable de una guerra estratégica 
por los signos que ha invadido el ejemplo más privilegiado de los paisajes hegemónicos de los Estados Unidos.

Al igual que el acto político de la alcaldesa, la muerte de Floyd nos recuerda que los EE.UU. no es moderno, y de hecho, todos los murales y monumentos de la nación no son más que "un fino velo para cubrir los crímenes que deshonrarían a una nación de salvajes" (Frederick Douglass). Pero su poderoso llamado a la humanidad fue la acumulación de los gritos de cientos de años de violación y sufrimiento, y de resistencia y supervivencia. Al hacerlo, se enganchó el velo que cubre la reivindicación de los EE.UU. de un orden democrático moderno, justo y equitativo. Volvió a emerger y exponer la larga sociedad fracturada de América que vive dentro de sus perímetros nacionalistas. De ahí que, hoy en día, las últimas palabras de Floyd "No puedo respirar" sirven para recordar la hipocresía que envuelve el aura de larga data alrededor de Washington, D.C., que siempre se ha abierto camino hacia un "paisaje democrático ideal" y que, también paradójicamente, nunca deja de ser la firma y el epítome del poder colonial. El hermoso paisaje de D.C. fue una herramienta de diseño que ha servido por mucho tiempo para enterrar y oscurecer la historia negra de la nación. Ha existido como una brillante codificación de la supremacía blanca y la frágil hegemonía. Y ahora, la plaza BLM pone en duda esta narrativa establecida del triunfo angloamericano a nivel nacional. La plaza proporciona una muestra de reconocimiento para todos aquellos que no se han sentido escuchados, y es una señal de que la construcción de una nueva 'democracia de la abolición' (Davis) está empezando a llamar la atención en los salones de baile y salas de juntas de los Estados Unidos.

\section{CODIFICANDO EL ESPACIO COLONIAL: ALGUNOS ANTECEDENTES HISTÓRICOS}

La historia del origen de la capital se alberga en un contexto histórico de profunda desigualdad, insensibilidad e indiferencia. Es el espacio donde la monumental supremacía blanca superpone las marcas de un orden imperial y racial. Sus orígenes, por lo tanto, se basan en la paradoja, la contradicción y la negación. Aunque la capital de la nación afirma ostensiblemente que EE.UU. es un país democrático, el proceso de diseño del DC nunca fue en absoluto democrático. No surgió de la imaginación popular, sino que fue George Washington (1732-1799), el primer presidente de los Estados Unidos, el que eligió hacer un centro federal. Decidió que el Distrito de Columbia, el núcleo del nuevo gobierno estaría junto al río Potomac, 13 millas al norte de Mount Vernon, su propia finca opulenta de 8.000 acres ("Acerca de Mount Vernon"). Pierre Charles L'Enfant, que fue reclutado en Francia para luchar en la Guerra Revolucionaria estadounidense y en quien Washington confiaba personalmente, diseñó Washington D.C. en 1791, siguiendo un estilo vernacular francés (Bowling, 2002). L'Enfant diseñó la ciudad ornamentada en estilo barroco, transponiendo elementos arquitectónicos coloniales franceses al paisaje norteamericano. Esta orquestación del espacio construido, su lenguaje monumental y los círculos y ejes superpuestos se derivaron directamente de los vocabularios de diseño colonial francés de esa época. El plan de L'Enfant no era simplemente colocar los edificios importantes y la gente de poder en lugares estratégicos basados en los contornos de las vías fluviales y las elevaciones cambiantes, sino también hacer una ciudad que pudiera ser 'hermosa' - lavar y empastar en color blanco sobre el hecho material de la profunda integración de la mano de obra negra en 
la construcción del centro de la capital y la presencia de la negrura en el paisaje circundante de la capital. Así, el D.C. de L'Enfant fue una ciudad ejemplar de poder que más tarde también fue emulada en la construcción de otras ciudades coloniales como la Nueva Delhi de Edwards Lutyen en la India. El biógrafo de L'Enfant, Scott Berg, señaló que su plan tenía por objeto hacer de la capital de la nación una ciudad de "paseo público", en la que "toda la ciudad se construyó en torno a la idea de que todos los ciudadanos eran igualmente importantes". (Berg citado en Fletcher, 2008). La idea de L'Enfant de un "paseo público para todos", paradójicamente, consagraba brutales asimetrías de inclusión y exclusión que siguen violando a todos los que llevan la carga de esta nación desde sus actos fundacionales de expropiación, genocidio, colonización, dominación forzosa, hambre impuesta y esclavitud (Dunbar-Ortiz, 2014). Al hacer realidad el sueño de Washington, L'Enfant buscó el ideal de cualquier buen moderno, la purificación del espacio (Latour, 1993). Su imaginación urbana se entrecruzó con los tiempos coloniales y los contextos sociales de violencia blanca, que promovieron la elevación de los espectadores de élite y, especialmente, los líderes de la comunidad de la blancura, que se verían inmersos en el placer visual y espacial asquerosamente privilegiado que las vistas, los paseos urbanos, las calles y el paisaje de D.C. proporcionaban a los despreocupados colonizadores. Por lo tanto, la oscuridad se ocultó de los espacios visibles del paisaje, y evidentemente para que el engaño del modernismo de los EE.UU. continúe, ¡debe permanecer oculta!

En la consolidación de su orden racial, hoy en día, D.C. es una ciudad de desigualdad racial. Conscientemente eleva sus edificios y monumentos icónicos mientras desfinancia los espacios e ignora las voces de las comunidades marginadas. Por lo tanto, el legado de la esclavitud siempre ha sido intencionalmente oscurecido. Consideremos como punto de partida, por ejemplo, la ordenanza de tierras de Jefferson de 1785 y la elaboración de la cuadrícula de Jefferson, una medición única de paisajismo que facilita los derechos de compra de tierras de cultivo, enterrando y borrando despiadadamente el conocimiento del género $o$ la raza de los trabajadores que laboraban en esas tierras. Esta fue la primera codificación supremacista de la infraestructura paisajística de los Estados Unidos. Confirmó un paisaje dividido y asimétrico en el que los actores blancos eran propietarios y los sujetos negros y morenos trabajaban. Esta fórmula paisajística impulsó la organización, el estudio y la división del espacio público y las tierras en todo el país y el diseño rectangular de los espacios urbanos como jardines, plazas, fuentes y grandes avenidas en ejes que dirigen la mirada a menudo a los edificios blancos, y termina en un foco que a menudo simboliza el poder y la propiedad blancos de los espacios públicos (Carstensen, (1987). En general y, consecuentemente, la proporción de espacio en todo el país siempre había sido un instrumento para un paisaje bastante ubicuo y divisorio, pero que simbolizaba engañosamente la democracia (el mito paradójico sostenido por Jefferson y otros de que el campesino blanco que trabaja junto a sus esclavos está en el centro de la consideración de la organización del orden político [Hofstadter, 1956]). Por lo tanto, D.C. brotó de una imaginación paisajística dominante centrada en los padres fundadores de la nación, los presidentes blancos, y sirvió para suprimir el otro lado, que es la negrura-un paisaje de los negros y los indígenas, que fue ignorado por la autoridad civil para ser invisible, oculto y tácito. Con el paisaje de las casas y haciendas de los presidentes diseñados en estilos neoclásicos, el paisaje de los blancos se extiende desde D.C. hasta Virginia, Carolina del Norte, Massachusetts, Tennessee, Nueva York y espacios de todo el Oeste. Las propiedades 
presidenciales de Virginia, como el Monticello de Thomas Jefferson en Charlottesville, el Montpelier de James Madison y la propiedad de Berkley del Presidente Benjamin Harrison, permanecen cerca de este núcleo gubernamental. Todas estas fincas, jardines y espacios públicos sirven para glorificar a los líderes de esta horrible fantasía colonial de los colonos, alimentando la pesadilla de la blancura, la superioridad, la violencia y la muerte en todo el paisaje. En contraste con estos últimos presidentes que todavía son celebrados en sus glorificados cementerios monumentales, los cementerios de sus homólogos negros e indígenas (sus consejeros, sus trabajadores, sus amantes prohibidos y servidumbre) fueron profanados, borrados o suprimidos con demasiada frecuencia. Los esclavos negros trabajaban como mano de obra oprimida en estos proyectos. ¡Fueron el trabajo fundacional sobre el que se construyó la Casa Blanca! Los signos de este trabajo están ahora inimaginablemente blanqueados en los registros públicos y en las cartillas de historia usadas en las escuelas. Innumerables cuerpos de esclavos desaparecieron en los bosques de estos paisajes, sin ser reconocidos y desterrados; estos cuerpos exigen una desesperada arqueología etnográfica de la mano de obra negra en la construcción de los E.E.U.U. Coloniales. Claman por una revelación del tortuoso pasado colonial para que podamos entender mejor su presente turbulento e hipócrita.

Este destierro de la mano de obra y la subjetividad de los negros e indígenas ha avanzado horriblemente desde la fundación del país de los colonos. Su bifurcación regional posterior a la Guerra Civil hacia el Norte-Sur continúa en las incesantes expulsiones actuales de los negros y morenos pobres en todas partes. El Norte triunfó, y así la esclavitud "terminó". Sin embargo, con un paisaje bifurcado, la emancipación seguía siendo en la práctica ilusoria, una especie de consigna, ya que la esclavitud no oficial, las cuadrillas de prisioneros y el complejo penitenciario dieron su fruto aterrador en toda la nación. La división social, la opresión y la violencia continuaron sistemáticamente de forma estructurada incluso después de la culminación de la guerra que muchos creían que traería la armonía y la emancipación final de la esclavitud. La herencia blanca de E.E.U.U. dominó la cultura popular, no por gestación accidental sino por constante fomento e instigación. Esta incitación hegemónica se ilustra en el pedaleo de recuerdos nacionalistas como el retrato del Presidente Washington incrustado en los sellos (1947) y la imagen del Presidente Jackson en el billete de veinte dólares que sirvió de pretexto para el asesinato extrajudicial de George Floyd.

A fines del siglo XIX y principios del XX, junto con la consolidación de Jim Crow, el paisaje de la blancura creció en su violenta prolijidad. Un poderoso ejemplo de esto puede identificarse con respecto a la monumentalización del espacio en Virginia. Los monumentos de la Guerra Civil se erigieron en Richmond, la capital de Virginia, en un esfuerzo concertado para consagrar y popularizar un paisaje palpable que evocara el pasado anterior a la Guerra Civil. El objetivo más amplio y grande, entonces, era valorizar a los héroes sureños de la Confederación invocando en la memoria colectiva la recuperación vanagloriosa de aquellos que habían perdido la consiguiente guerra interna por la esclavitud. ¿Pero de la memoria colectiva de quién fue evocada? La Monument Avenue de Richmond, por ejemplo, fue diseñada como un bulevar arbolado y cubierto de hierba, salpicado de estatuas de veteranos de la Confederación de Virginia de la Guerra Civil norteamericana (la blancura por sí sola fue suficiente para redimir a estas figuras en conflicto, según algunos, de su traición y terrorismo contra el Estado en desarrollo). Muchos de los diseños siguieron el modelo de las calles 
coloniales de Inglaterra, y las estatuas reflejan las establecidas por los británicos en la India colonial y en todo su imperio como símbolos de orgullo (Cannadine, 2001). A pesar de las objeciones de los miembros negros del Consejo Municipal de Richmond, la ciudad se apropió de espacios para la dedicación de cinco monumentos de J. E. B. Stuart, Jefferson Davis, Thomas Jackson, Matthew Fontaine Maury, y de esa figura más influyente y provocadora, el general Robert E. Lee, en la época de la era de Jim Crow (Griego, 2015; Driggs, Wilson, \& Winthrop, 2001). Archer Anderson, de la Asociación del Monumento a Lee, dijo que la ciudad había "dedicado el Monumento a Lee no como un recuerdo a la Confederación, sino como un testamento al 'honor personal', 'esperanza y alegría patriótica' y a un 'líder ideal'" (Griego, 2015). ¿Pero de quién es el pasado patriótico? ¿Y de quién es el orgullo que se promulga a costa de tanto dolor y violencia?

En la elaboración material y discursiva del vernáculo de la Blancura, estas estatuas ecuestres de la Confederación se han convertido en símbolos que idolatran la supremacía racial, el odio y el racismo de la Confederación. Inversamente, su erección y valorización han tenido un gran costo para los negros y los morenos, ya que estos monumentos fomentan silenciosamente las violaciones raciales a través de los paisajes, asegurando una mayor violencia epistémica. En su exultación y codificación de los vencedores de la historia (en realidad, los perdedores renacidos y los traidores de la Guerra Civil estadounidense) continúan la larga trayectoria de la supresión de la subjetividad, la negritud y la iconografía negra en el paisaje americano.

La potencia y la soberanía de la Blancura están aseguradas y establecidas por medio de estas estatuas. Los campus institucionales, como la Universidad de Virginia en Charlottesville, tienen monumentos de guerra como las estatuas de Robert E. Lee y Thomas "Stonewall" Jackson, que están protegidos por la ley estatal. A ellos hay que añadir la letanía de pinturas de propietarios de élite, miembros de la aristocracia rural de las plantaciones y los banderines y emblemas de celebración que idealizan la época colonial y que se encuentran dispersos en las propiedades de la universidad, no sólo en el Sur sino también en el Norte. Muchas de estas figuras, a menudo benefactoras de las universidades de los Estados Unidos, obtuvieron sus beneficios de operaciones en alguna parte del universo de la esclavitud. Estas figuras poderosamente simbólicas ahora sirven a menudo para despertar más violaciones raciales. Estos espacios cargados de emoción imponen una fuerza excesiva del paisaje que es comparable a la fuerza física que los agentes de policía infligieron a George Floyd y a otros como Eric Garner (2014).

Pero la guerra por los signos que provoca la monumentalización no termina ni puede terminar con los "vencedores de la historia". Tal lucha sobre la iconografía del pasado y el presente está marcada por rupturas y discontinuidades. Hay una corriente de resistencia contra el grano de la cultura dominante, como afirma Gramsci, "una guerra de maniobras". Es la larga revolución que fue ordenada por aquellos miembros negros del Consejo de la Ciudad de Richmond de finales del siglo XIX, como John Mitchell, quien se resistió a la instalación de estatuas que convertirían en héroes a "traidores blancos" como Robert E. Lee:

Los hombres que más hablan del valor de Lee y de la sangre de los valientes muertos confederados son los que nunca han olido pólvora ni han participado en una batalla. La 
mayoría de ellos estaban en una mesa, ya sea encima o debajo de ella cuando la guerra estaba en marcha... (Mitchell citado en Griego, 2015)

\section{UNA CURVA EN EL RÍO DE LA HISTORIA}

En el resplandor del actual levantamiento contra la incesante brutalidad de la policía, y después del sufrimiento de tantas violaciones y asesinatos a lo largo de la historia negra, la protesta provocada por la muerte de Floyd consiguió ensuciar el velo que cubría el paisaje de la negrura. Se hace eco de los profundos anhelos existenciales de la larga duración de la lucha negra contra los espacios confinados y la monumentalización impuesta. El 5 de junio de 2020, en medio del contexto de una poderosa indignación de la comunidad, la alcaldesa afroamericana de D.C., Muriel Bowser, decidió publicar textos visibles a nivel nacional en letras gigantescas que intentaban captar el espíritu de "Black Lives Matter" en dirección a la Casa Blanca. Y posteriormente renombraría la Plaza Lafayette como "Black Lives Matter Plaza". Este gesto iconoclasta ciertamente asesta un golpe contra la maligna estatua ecuestre de Andrew Jackson de la Guerra de 1812 que era el centro de atención de la plaza, ahora repudiada en la nueva BLM Plaza. También cataliza en el terreno cívico un posible paso hacia la recuperación de la negrura en Monument Avenue, frente al trágico paisaje nacionalista de E.E.U.U. El 4 de junio, en respuesta al masivo desbordamiento de ira devastada por la muerte de Floyd, el gobernador de Virginia, Ralph Northam, prometió retirar la icónica estatua del General Lee. 


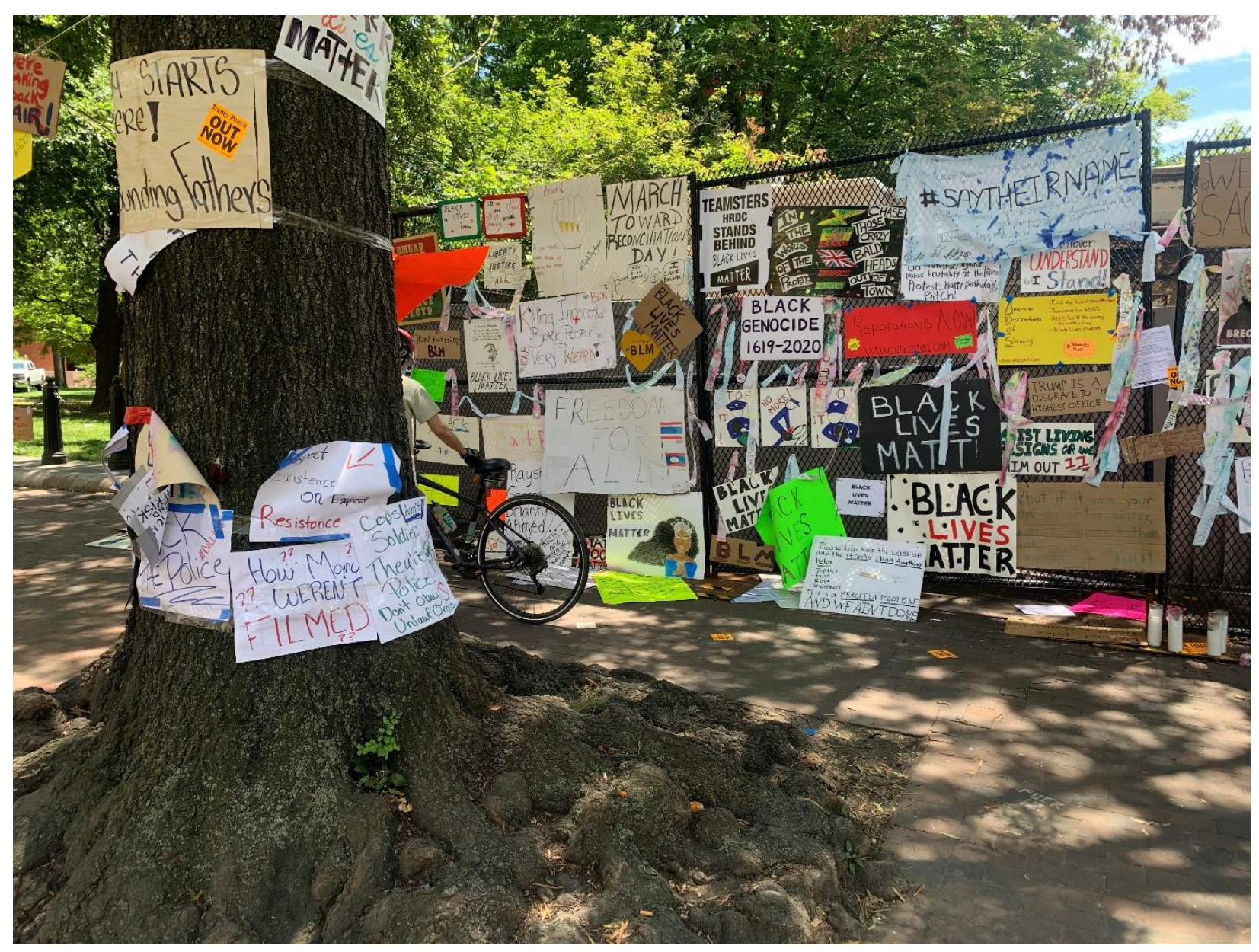

Figura 2. La reja de la Casa Blanca y el umbral entre el reino público y el privado se convierte en una forma de paisaje curativo, foto cortesía de Stephanie Leedom

Esta decisión histórica, si es que es implementada, cambiará el significado del paisaje nacionalista blanco de D.C., aguijoneando un poco su blancura, o más bien indicando el muy largo camino hacia otra posibilidad. Otros líderes de Virginia también se han comprometido a derribar las otras cuatro estatuas confederadas a lo largo de la prominente Monument Avenue, cambiando el significado afirmado que desafortunadamente ha triunfado por más de un siglo. Los umbrales de las rejas en las áreas de la plaza sin ningún capricho de los diseñadores puede que un día se conviertan también en un paisaje curativo de lágrimas y alegría (Fig.2). La muerte de Floyd hace eco del llamado de la resistencia al genocidio impulsado por el estado. Tal llamado reverbera en el alegato no sólo por la justicia, sino también por el desfinanciamiento y desmantelamiento de estas tecnologías y aparatos de opresión y violencia estatal. El empuje de estos acontecimientos ejerce una enorme presión discursiva y material sobre las formas dominantes de monumentalización de los paisajes en los Estados Unidos y en todo el mundo. Pone en suspensión histórica aquellos molestos enigmas e hipocresías que siempre han afligido al diseño del paisaje dominante en este país. Y pone en evidencia la carga de la brigada ligera de intervenciones de lienzos y etiquetas de diseñadores y activistas no diseñadores que no sólo golpean en categorías por encima de su capacidad, sino por su derecho a ser reconocidos. El llamado de la humanidad a la memoria de George Floyd ondea a través del espacio y el tiempo, instando a un reconocimiento del 
mundo conocido por parte de un grupo mixto de diseñadores y no diseñadores, viejos y jóvenes, personas de todos los géneros, esferas, modos de ser clasificados y racializados bajo el estandarte de las banderas, programas de cambio, perspectivas y actitudes variadas. ¡Desde los años 60 que los procesos de diseño público en el espacio de la ciudad no han sido sometidos a tanta presión cultural y material!

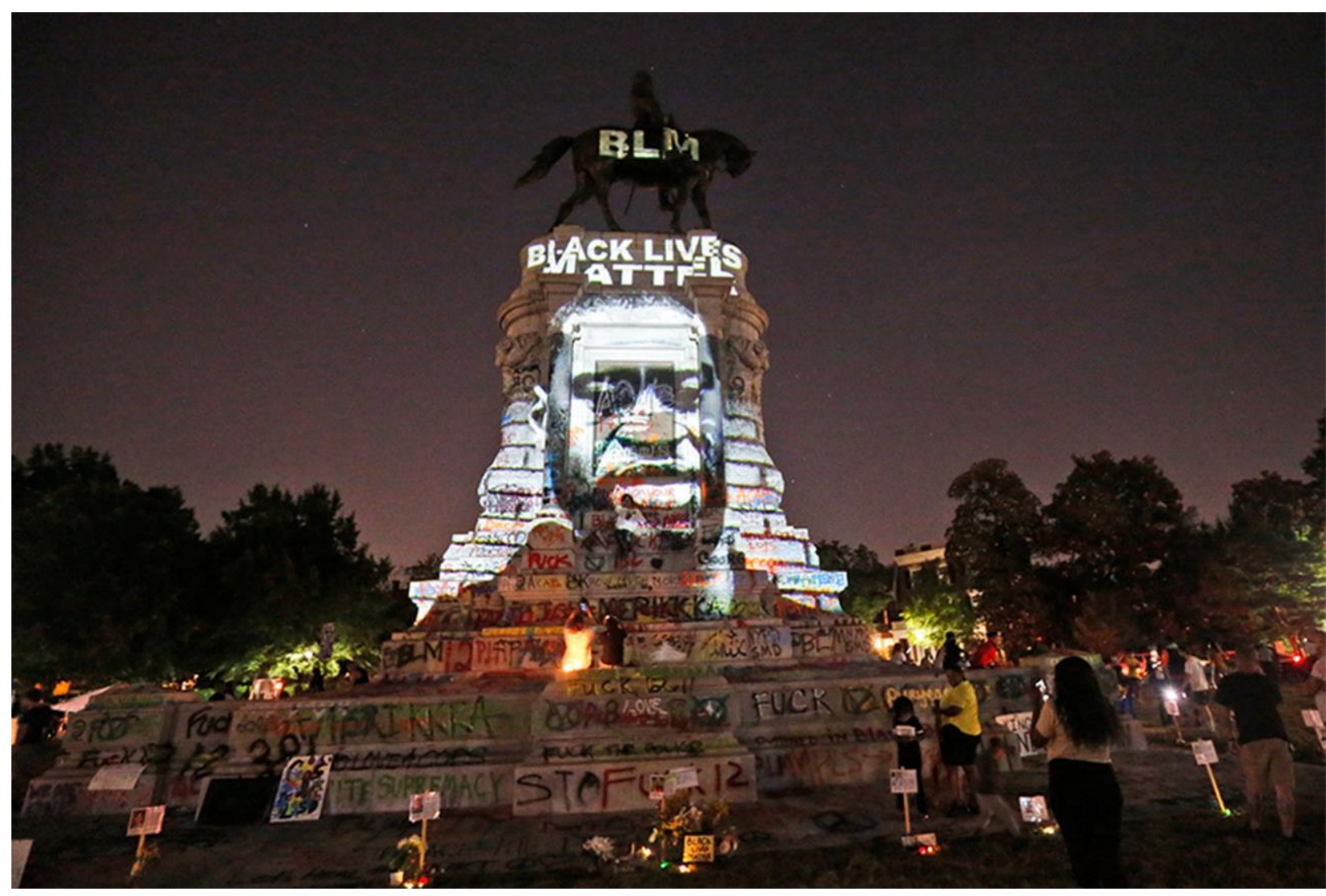

Figura 3. La cara de George Floyd superpuesta en la estatua del General Lee en Monument Avenue, Richmond, foto: Internet, New York Post 10 de julio de 2020

\section{CONCLUSIÓN: LAS VIDAS Y LOS PAISAJES NEGROS SIEMPRE HAN IMPORTADO}

En el siglo XXI, estos paisajes de blancura continúan con la negación de la historia de todos los oprimidos. Por eso hoy decimos que "las vidas y los paisajes negros siempre han importado"; y se seguirá luchando por las condiciones de la vida social hasta que se logren y se desmantelen todos los sistemas de opresión, incluidos la policía y los sistemas de estado policíaco. A partir de estas intervenciones sociales, económicas, políticas y de paisaje, la gente reconoce la parte connotativa y de poder de nuestro paisaje social. Este cambio es un pequeño paso hacia la emancipación después de una larga y sofocante historia, y también una reafirmación y reclamación contra la opresión estatal, que mantendrá su fortaleza mientras los sistemas de violencia impulsada por el Estado, la policía y la negligencia intencional de los tratados violados no sean reconocidos ni se rindan cuentas por ellos. Las últimas palabras de George Floyd "No puedo respirar", como un grito de la humanidad, devuelve la mirada de L'Enfant, descifra el paisaje colonial codificado y está siendo recordado en la recuperación de 
los espacios públicos, los paisajes nacionalistas blancos de D.C. El paisaje desigual de la blancura se reconoce dentro del contexto y el significado histórico. A medida que las protestas estallan en DC, su espíritu se extiende por todo el mundo. Muchas otras comunidades y pueblos están pidiendo un encuentro y un reconocimiento de la historia y de la miríada de paisajes vergonzosos, supremacistas, coloniales y opresivos. Hoy en día, las masas exigen la retirada de las controvertidas estatuas confederadas de todo el país; estatuas terribles saturadas de las glorificaciones de la injusticia como la estatua ecuestre de Robert E. Lee en Richmond, Virginia o los Texas Rangers en Dallas. En comunidades globales como las de Francia, Inglaterra y Bélgica, los manifestantes también han pedido la confiscación de sus estatuas coloniales. En Bélgica, los manifestantes han exigido que se retire la estatua del brutal colonizador, el Rey Leopoldo II, uno de los primeros "líderes" en ser recordado por "crímenes contra la humanidad" (Williams, 1985). En Francia, los manifestantes salpicaron con pintura roja la estatua del revolucionario francés Voltaire, que era el propietario de importantes plantaciones coloniales. Y en Inglaterra, la estatua del comerciante de esclavos Robert Millington y el colonialista Cecil Rhodes también han sido objeto de un rechazo público similar. Por lo tanto, sacudiendo el núcleo de nuestra conciencia, que muchos han ignorado durante mucho tiempo, llegamos a un reconocimiento de las viejas formas de organización espacial hegemónica como "Las vidas negras y el paisaje siempre han importado".

Lo que se recuerda con fuerza, en relación con estos desarrollos, es el poder generativo de la lucha negra en los EE.UU., su capacidad para sostener una antorcha de escrutinio a la condición moderna en todos los EE.UU. y en todo el mundo. Esta lucha, como indicamos en este artículo, se está llevando a cabo en este momento, como siempre ha sido, en muchos frentes poderosamente articulados al espacio. Desafía no sólo la monumentalización del espacio en el que la supremacía y hegemonía blanca se han grabado en el paisaje, codificando una terrible relación de los poderes coloniales de los colonos con la gente aterrorizada y exaltando la despreciable supremacía blanca sobre los intereses humanos de los sujetos oprimidos y marginados en todas partes. También desafía los rimbombantes símbolos de una organización cívica a otra. Así, desafía obedientemente las acciones socialmente insignificantes de la alcaldesa de Washington, D.C., quien pensó que unas pocas marcas en el pavimento podrían distraer a la gente del verdadero trabajo que hay que hacer: desarmar y desmantelar todos los sistemas de opresión y violencia impulsados por el Estado. La instalación líquida de "Black Lives Matter", hecha más firme al agregar "= Desfinanciar la Policía", y la elevación de la Plaza BLM, no sólo frente a la Casa Blanca sino en las agendas de muchos en todo el mundo, sirven para estimular las conciencias de aquellos auto-satisfechos con las relaciones "purificadas" de los colonos de la sociedad "Moderna". Proyectan una agenda alternativa de reconocimiento político contra la larga duración de la Supremacía Blanca a través de los paisajes, prácticas y ejecución estatal en nuestras ciudades. Recuerdan a muchos que se levanten contra el grotesco reordenamiento del espacio que la formulación de políticas neoliberales ha prescrito en el espacio de la ciudad y los sistemas de policía que esperan, desesperadamente, mantenerlo. A pesar de sus innumerables defectos, la Plaza BLM sirve de aviso sobre un statu quo que ya no es sostenible. 


\section{BIBLIOGRAFÍA}

About Mount Vernon. Mount Vernon. Recuperado en Julio 2, 2020, from https://www.mountvernon.org/about/

Adelson, C.E. (1970, Marzo). James Baldwin and Istanbul: A love affair. Ebony 25(5), pp. 4046.

BlackLivesMatter DC [@DMVBlackLives]. (2020, June 5). This is performative and a distraction from her active counter organizing to our demands to decrease the police budget. [Tweet].

Twitter. https://twitter.com/DMVBlackLives/status/1268894229369061382

BlackLivesMatter DCa [@DMVBlackLives]. (2020, Junio 8). .@andersoncooper @MayorBowser was correct, she placed \#BlackLivesMatter in front of the White House for white liberals to enjoy \& play dead on her Mural. [Tweet]. Twitter. https://twitter.com/DMVBlackLives/status/1270266757274624000

Donald J. Trump. [@realDonaldTrump]. (2020, Julio 1). ....horrible BLM chant, "Pigs In A Blanket, Fry 'Em Like Bacon". Maybe our GREAT Police who have been neutralized. [Tweet].

Twitter. https://twitter.com/realDonaldTrump/status/1278324681477689349

Project for Public Spaces [@PPS_Placemaking]. (2020, Junio 8). This weekend, protestors reclaimed the message, repainting the mural to say "Black Lives Matter = Defund the Police." [Tweet].

Twitter. https://twitter.com/PPS_Placemaking/status/1270028530211074051

Bowling, K.R. (2002) Peter Charles L' Enfant: Vision, honor and male friendship in the early American republic. Washington DC: The Friends of GW Libraries.

Cannadine, D. (2001). Ornamentalism: How the British saw their empire. Oxford, UK: Oxford.

Carstensen, V. (1987) Patterns on the American land. Journal of Federalism 18(4), pp. 31-39.

Davis, A. Y. (2011). Abolition democracy: Beyond empire, prisons, and torture. Seven Stories Press.

Douglass, Frederick. (1852, Julio 5). "The Meaning of July Fourth for the Negro" Speech. Recuperado de www.pbs.org

Driggs, S.S., Wilson, R.G., Winthrop, R. P. (2001). Richmond's Monument Avenue. Chapel Hill, N.C.: University of North Carolina.

Dunbar-Ortiz, R. (2014). An indigenous peoples' history of the United States (Vol. 3). Beacon Press. 
Fletcher, K.R. (2008, Abril 30). A brief history of Pierre L'Enfant and Washington, D.C.: How one Frenchman's vision became our capital city. The Smithsonianmag.com. https://www.smithsonianmag.com/arts-culture/a-brief-history-of-pierre-lenfantand-washington-dc-39487784/ descargado en Junio 22, 2020)

Gilman, N. (2003). Mandarins of the future: Modernization theory in cold war America. Baltimore, MD: John Hopkins.

Griego, T. (2015, Junio 25). Past and present: The many-sided history of the Monument Avenue debate. https://richmondmagazine.com/news/news/monument-avehistory/ (descargado en Junio 22, 2020)

Higgins, Tucker and John W. Schoen (2020, Junio 1). These 4 charts describe police violence in America. CNBC. https://www.cnbc.com/2020/06/01/george-floyd-death-policeviolence-in-the-us-in-4-charts.html

Hofstadter, R. (1956). The myth of the happy yeoman. American Heritage 7 (3), pp. 43-53.

Latour, B. (1993). We have never been modern. Cambridge, MA: Harvard.

Loring, Donna M. (2017, Mayo 8). Andrew Jackson: the Father of Genocide of the South and Eastern Tribes. Indian Country Today. Recuperado de https://indiancountrytoday.com/archive/andrew-jackson-the-father-of-genocideof-the-south-and-eastern-tribes-HW7MTDBwi0y-FJbiSrJPzg

Massey, D. (1993). Power geometry and a progressive sense of place. En J. Bird, B. Curtis, T. Putnam, G. Robertson, \& L. Tickner (Eds.), Mapping the futures (pp. 59-69). London: Routledge.

Williams, G. W., \& Franklin, J. H. (1985). George Washington Williams: A Biography.

Willingham, A.J. (2020, Junio 5). Washington, DC paints a giant 'Black Lives Matter' message on the road to the White House. CNN. Recuperado de https://www.cnn.com/2020/06/05/us/black-lives-matter-dc-street-white-housetrnd/index.html 